\title{
A TACTICAL/STRATEGIC LEVEL COST ANALYSIS BASED ON VISIT TIME PREFERENCES FOR VEHICLE ROUTING PROBLEM WITH SIMULTANEOUS PICKUP AND DELIVERY
}

\author{
Mustafa DEMİRBiLEEK ${ }^{*}$
}

\begin{abstract}
Vehicle Routing Problem with Simultaneous Pickup and Delivery (VRPSPD) has been studied for long years and used to model for many real-life applications. The problem is basically to find optimal routes for vehicles that serve customers in a service area to collect as well as deliver goods at the same time. Many logistic companies such as cargo, post, online supermarket, etc. face this problem in their daily operations. Because of high competitions in the sector, companies start to provide visit time preferences that customers can select. Although this is highly preferred by customers, it causes additional costs for companies since it is highly probable that preferences of customers violate optimal routes of vehicles. This problem is called as VRPSPD in Time Windows (VRPSPDTW). In this study, we develop a tactical/strategic level pricing policy based on calculation of additional travel time cost caused by visit time preferences of customers. Idea behind the policy is that solving VRPSPD for same customer set with/without considering time windows in each trial. After conducting many trials for different customer sets, average differences between travel times of VRPSPD and VRPSPDTW are determined. A generic hourly additional prices based on the average differences are calculated. Both problems are modelled as mixed integer linear programming models and solved with CPLEX 12.9. Differences among travel times vary from 32 to 180 minutes according to experimental settings. Furthermore, results do not only change with time windows, but also different service regions play important role on results.
\end{abstract}

Key words: Vehicle Routing Problem with Simultaneous Pickup and Delivery, Cost Analysis, Mixed Integer Linear Programming Model

\section{Introduction}

Vehicle Routing Problem (VRP) has been studied since the study of Dantzig and Ramser [1], "The Truck Dispatching Problem", 1959. The problem was to find optimal routes for vehicles that deliver gasoline from a bulk terminal to many gasoline stations. Many different extensions such as multidepot, capacity, time windows, stochastic service and travel times as well as solution methods such as the linear programming, mixed integer programming, saving heuristics, tabu search, genetic algorithm have been proposed since then [2]. One of most studied extensions of VRPs is simultaneous pickup and

\footnotetext{
${ }^{1}$ Assistant Professor, Department of Industrial Engineering, Gaziantep Islam Science and Technology University, Gaziantep, TURKEY, (mustafa.demirbilek@ gibtu.edu.tr) (Dhttps://orcid.org/0000-0002-1520-2882 
delivery (VRPSPD). The main consideration is to collect some goods from customers when delivering some products simultaneously [3]. As in many other VRPs, the main aim is to minimize travel times of vehicles. The main constraint is to satisfy delivery and pickup demands of customers by considering capacity of vehicles. Many logistic companies face the same problem in the industry due to scarce resources, environmental sensitivities, and regulations. The online order system of grocery stores is a good example for VRPSPD. Orders are distributed to customers while same vehicles pick up undated goods or empty bottles. Another sector as an example for VRPSPD is the reverse logistics. Because of regulations, some companies are responsible products during their whole life cycles (as in the disposal of laser printers' cartridges) [4].

In VRPSPD studies, researchers are mostly dedicated to find optimum routes for vehicles under assumption of that customers accept service times companies offer. However, customers want to choose service times since they do not want to stay at homes or workplaces during whole days by waiting get their parcels collected and delivered. Therefore, many companies start to offer service time intervals customers can select to be visited. This problem is called as VRPSPD in Time Windows (VRPSPDTW). Although this is highly preferable for customers, it also makes routing activities more difficult and expensive for companies. Therefore, it is important that companies know how provided time windows effect overall costs.

In this study, we figure out how provided service time windows change overall costs in terms of travel times. Two important problems we must take into consideration are VRPSPD and VRPSPDTW. The methodology is to compare average travel times of VRPSPD with VRPSPDTW for same experiment settings. By repeating these comparisons many times, we calculate average additional costs caused by provided time windows for customers. The main aim is to determine a generic price policy for visits if we offer service time windows to customers. Notice that the pricing strategy in here is tactical or strategic levels against many studies in the literature that focus on pricing individual visits [5]. The next section, we demonstrate most related studies in the literature. In Section 3, mathematical models are formulated and explained. We discuss experimental settings and results in Section 4. Finally, some important facts and limitations are mentioned in the Conclusion Section.

\section{Literature Review}

According to our literature review, there is no study that considers costs caused by offered service time windows in the mid-term or long-term operations of companies. Since VRPSPD and VRPSPDTW are main parts of the solution, we review some key studies about them in the literature.

\subsection{Vehicle Routing Problem with Simultaneous Pickup and Delivery (VRPSPD)}

VRPSPD studies began with the study of Min [6], "The Multiple Vehicle Routing Problem with Simultaneous Delivery and Pickup Points", 1989. He optimized routes of vehicles that delivered library materials from a main library to 22 branches and pick up the materials from branches to carry to the main library. Goksal et al. [7] proposed a discrete particle swarm optimization method and variable neighborhood descent algorithm for VRPSPD. The method kept swarm diversity when improving randomly selected solutions in each iteration. Montane and Galvao [4] modified a tabu search algorithm to become compatible with VRPSPD. Yazgan and Buyukyilmaz [8] proposed a greedy heuristic solution 
methodology and conducted a regression analysis to be able to seek the relationship between travel distances and the number of customers and capacity of vehicles. The greedy heuristic adding the nearest customer into the tour of a vehicle if it is feasible in terms of delivery and pickup demands of the customers. Kececi et al. [9] proposed a mixed integer linear programming formulation and Clark and Wright heuristic algorithm for the solution. They considered heterogenous vehicle fleet, covered different type of vehicles in terms of capacity and cost, against many studies in the literature. They adapted the heuristic algorithm to consider capacity restrictions of vehicles and delivery as well as pickup demands of the customers. Hezer and Kara [10] modified the Bacterial Foraging Optimization Algorithm to solve VRPSPD by considering discrete nature of the problem. Their method gave superior results for 24 out of 40 test instances compared to the construction heuristic of Dethloff [3]. Kalayci and Kara [11] developed a hybrid algorithm based on the combination of ant colony system and variable neighborhood search. Since many studies exist in the literature, we refer interested readers to the review study of Koc and Laporte [12] in that VRPSPD studies were classified in terms of models, solution methods, variants, industrial applications and case studies.

\subsection{Vehicle Routing Problem with Simultaneous Pickup and Delivery in Time Windows (VRPSPDTW)}

Studies for VRPSPDTW are recent and quantitatively less compared to VRPSPD since the time window constraint makes the problem more difficult. The first publication that considered time window issue in VRPSPD was the study of Angelelli and Mansini [13], "The Vehicle Routing Problem with Time Windows and Simultaneous Pick-up and Delivery", published in 2002. They used a branch and bound solution approach for a 20-customer problem set. Lagos et al. [14] proposed a particle swarm optimization algorithm for VRPSPDTW. Cetin and Gencer [15] developed a mathematical model. They aimed minimizing waiting times instead of travel times in the study. In their other study [16], heterogeneous vehicle fleets were taken into consideration for VRPSPDTW. They considered vehicles with different capacity levels and costs when minimizing waiting times. Wang et al. [17] considered a multi-objective perspective that covered number of vehicles, total travel distance, makespan, waiting time, and delay time. They used a real-life data derived from a company and proposed two solution methodologies, multi-objective local search and memetic algorithm. Wang et al. [18] developed parallel simulated annealing algorithm that included a residual capacity and radial surcharge insertion-based heuristics. Liu et al. [19] modified VRPSPDTW for home healthcare problem that considered to visit patients in their homes by delivering some medicine to patients and picking up test samples to return healthcare centers. They proposed the genetic algorithm and tabu search methods for solutions.

For both problems, researchers mostly suggested heuristic/metaheuristic solution methods since the VRP and its variants are in NP Hard class and exact solution methods can be used for small-size problems. However, heuristic/metaheuristic solution methods do not guarantee optimal solutions. In our study, it is important that differences between results of VRPSPD and VRPSPDTW are raised from time windows for same data sets. Therefore, we use mixed integer linear programming models to solve both problems. 


\section{Material and Method}

The mathematical model is mostly same for both problems, but we must add some constraints to satisfy time windows for each customer. First, the mathematical model for VRPSPD is introduced. Next, we show additional constraints for VRPSPDTW under a separate section.

\subsection{The Mathematical Formulation for VRPSPD}

We have $n$ customers that must be visited by $k$ homogeneous vehicles. Each customer has a certain amount of pickup and delivery. When a vehicle visits a customer, the amount of pickup and delivery demands of a customer cannot exceed capacity of the vehicle. Vehicles must start from and return to the depot. The mathematical formulation for VRPSPD is mostly taken from the study of Montane and Galvao [4]. On the other hand, the maximum distance constraint is removed and the maximum daily working time and service time are added into the model. Followings show notations and decision variables:

\section{Notations:}

$\mathrm{V}$ : set of customers

$\mathrm{V}_{0}$ : set of customers and the depot

$\mathrm{K}$ : set of vehicles

$c_{i j}$ : distance between locations of customers $i$ and $j$

$p_{j}$ : pickup demand of customer $j, \forall j \in \mathrm{V}$

$d_{j}$ : delivery demand of customer $j, \forall j \in \mathrm{V}$

Q: vehicle capacity

T: working time limit for vehicles

S: service time

\section{Decision Variables:}

$x_{i j k}=1$, if vehicle $k$ moves from customer $i$ to $j$. 0 , otherwise.

$y_{i j}=$ Cumulative amount of pickup at node $i$ and transported in $\operatorname{arc}(i, j)$

$z_{i j}=$ Cumulative amount of delivery at node $i$ and transported in $\operatorname{arc}(i, j)$

The corresponding mathematical formulation is given by

Minimize:

$$
\sum_{k}^{K} \sum_{i}^{V_{0}} \sum_{j}^{V_{0}} c_{i j} x_{i j k}+\sum_{k}^{K} \sum_{i}^{V_{0}} \sum_{j}^{V_{0}} S x_{i j k} \quad i \neq j
$$

Subject to:

$$
\begin{gathered}
\sum_{k}^{K} \sum_{i}^{V_{0}} x_{i j k}=1, \quad \forall j \in \mathrm{V} \\
\sum_{i}^{V_{0}} x_{i j k}-\sum_{i}^{V_{0}} x_{j i k}=0, \quad \forall j \in V_{0}, \forall k \in K, i \neq j \\
\sum_{j}^{V} x_{0 j k} \leq 1, \quad \forall k \in K
\end{gathered}
$$




$$
\begin{gathered}
\sum_{i}^{V_{0}} y_{i j}-\sum_{i}^{V_{0}} y_{j i}=p_{j}, \quad \forall j \in \mathrm{V} \\
\sum_{i}^{V_{0}} z_{i j}-\sum_{i}^{V_{0}} z_{j i}=d_{j}, \quad \forall j \in \mathrm{V} \\
y_{i j}+z_{i j} \leq Q \sum_{k}^{K} x_{i j k}, \quad \forall i, \forall j \in \mathrm{V} \\
\sum_{i}^{V_{0}} \sum_{j}^{V_{0}} c_{i j} x_{i j k}+S \sum_{i}^{V_{0}} \sum_{j}^{V_{0}} x_{i j k} \leq T, \forall k \in K, i \neq j \\
x_{i j k} \in\{0,1\}, \quad \forall i, \forall j \in \mathrm{V}_{0}, \forall k \in K, i \neq j \\
y_{i j}, z_{i j} \geq 0, \quad \forall i, \forall j \in \mathrm{V}_{0}, \quad i \neq j
\end{gathered}
$$

The objective function (1) is to minimize total travel and service times. Constraints (2) make sure that each customer is visited by exactly one vehicle. Constraints (3) ensure that the same vehicle arrives and departs from each customer. Constraints (4) show the maximum number of vehicles allowed. Constraints (5) and (6) are flow equations for pick-up and delivery, respectively; they guarantee that both are satisfied for each customer. Constraints (7) ensure that pickup and delivery demands do not exceed capacity of the vehicle moving from customer $i$ to $j$. Constraints (8) show travelling and service times for a vehicle do not exceed the allowed working time. Constraints (9) and (10) demonstrate boundaries of decision variables.

\subsection{The Mathematical Formulation for VRPSPDTW}

As we mentioned before, the mathematical representation of VRPSPDTW is similar to VRPSPD in terms of subtour elimination, pickup and delivery flows, capacity of vehicles, etc. Moreover, we have same objective, minimizing daily travel and service times. Notations, the decision variable, and constraints related to time windows are as following:

\section{Notations:}

$e_{j}$ : earliest visit time to customer $j, \forall j \in \mathrm{V}$

$l_{j}$ : latest visit time to customer $j, \forall j \in \mathrm{V}$

M: a large number

Decision Variables:

$s_{i k}=$ Visit time of vehicle $k$ to node $i$

Subject to:

$$
\begin{gathered}
s_{0 k}+c_{0 i}-s_{i k} \leq M *\left(1-x_{0 i k}\right), \quad \forall i \in \mathrm{V}, \forall k \in K \\
s_{j k}+c_{j i}+S-s_{i k} \leq M *\left(1-x_{j i k}\right), \quad \forall i, \forall j \in \mathrm{V}, \forall k \in K \\
e j \leq s_{j k} \leq l j \quad \forall j \in V, \forall k \in K \\
s_{i k} \geq 0, \quad \forall i \in V_{0}, \forall k \in K, \quad i \neq j
\end{gathered}
$$


Constraints (11) and (12) demonstrate that visit time of a vehicle to a customer must be greater or equal than sum of visit time of previous customer or depot, service time (if the previous node is not the depot) and travelling time. Constraint (13) guarantees that the visit time of a vehicle to a customer is in the allowable time window. Constraint (14) shows boundary of the decision variable.

\section{The Research Findings and Discussion}

In this section, we explain test settings. Next, results of tests are demonstrated and discussed.

\subsection{Test Settings}

As we explained before, we basically analyze how offered time windows make differences on results compared to same problem without time windows. To test both models only for one customer set does not provide accurate results since results can significantly change for another customer set. Therefore, we conduct 30 sets that include different customers data. For each test, locations of customers, time windows, pickup and delivery demands are changed. It can be considered as operations of a company for 30 days. Note that same data is used for VRPSDP and VRPSDPTW in each trial. We have only time windows assigned to each customer in VRPSDPTW. The remaining data, locations of customers, pickup and delivery demands, etc. are identical for VRPSDP. However, data sets vary trial by trial for both problems.

Three different service area are considered. Total area size is $3481 \mathrm{~km}^{2}(59 \mathrm{kmX} 59 \mathrm{~km})$ and represented, $X \in[1,60]$ and $Y \in[1,60]$, in the coordinate system. In the first area type (R), customer requests can be arrived from anywhere equally likely. Next, customer requests can be arrived from only three clusters in the service area (C). Finally, $70 \%$ of customer requests can be arrived from three clusters and other requests can arrive from the remaining of the area equally likely (RC). The depot is located at the middle of the service area.

Each vehicle spends 5 minutes for servicing (S) at each customer location. Daily working time (T) for each vehicle is 480 minutes. We test three different time windows, 60, 120, and 240 minutes. In other words, the gap between the earliest service time and latest service time can be 60, 120 or 240 minutes. We assume that each customer chooses a time window that the service is provided in VRPSDPTW. For example, a customer can select 10-11 am or 1-2 pm if we offer 60-minute time windows. It means that that customer must be visited between 10 and $11 \mathrm{am}$, no earlier or later than these times. If time windows are 120 minutes, customer can select 9-11 am or 1-3 pm or etc. For 240minute time windows, customers can only decide whether they are serviced in morning or afternoon.

Two customer sets, 25 and 35, are considered. Delivery demands of customers are assigned uniformly between 3 and 9 packages, and pickup demands are assigned uniformly between 1 and 8 packages. We have different number of vehicles depending on the number of customers. Each vehicle capacity is 80 packages. The number of vehicles changes such a way that all customers can be visited by satisfying their pickup and delivery demands and time windows. All related data are shown in Table 1 . 
Table 1. Test settings

\begin{tabular}{|l|c|}
\hline Daily working time(minute) & 480 \\
\hline Service time(minute) & 5 \\
\hline Service area & $X \in[1,60]$ and $Y \in[1,60]$ \\
\hline Number of customer & 25 and 35 \\
\hline Number of vehicle & 4 \\
\hline Vehicle capacity(package) & 80 \\
\hline Pickup demand(package) & Uniform $(1,8)$ \\
\hline Delivery demand(package) & Uniform $(3,9)$ \\
\hline Time window(minute) & $60,120,240$ \\
\hline
\end{tabular}

\subsection{Results}

First, the mixed integer linear programming is coded with AMPL (A mathematical programming language) IDE 3.5 software and solved with CPLEX 12.9. Test sets are solved in a PC with Intel i5 7200U 2.5 GHz CPU and 8 GB Ram. Tables 2, 3 and 4 show results of VRPSDP and VRPSDPTW under different number of customers and service regions for 60, 120, and 240-minute time windows. $95 \%$ confidence intervals $(\mathrm{CI})$ are provided for results of both problems. Moreover, independent sample t-tests are conducted and calculate p-values for each pair to understand whether the results are statistically different. Our null hypothesis is that the average travel times of VRPSDP is equal to the average travel times of VRPSDPTW with 60, 120, and 240-minute time windows. Therefore, the alternative hypothesis is that the average daily visit of VRPSDP is different from the others. We use Microsoft Excel for t-tests and calculations of CIs.

Table 2 demonstrates results for the 60-minute time windows. First, p-values are much lower than the threshold value, 0.05 . Thus, we can reject the null hypothesis and say average travel times of problems are statistically different. At first sight, differences between results varies from approximately 100 to 180 minutes based on the type of region and the number of customers. $80 \%$ increase proves how other factors beside time windows can affect results. Clustered service areas (C) provide shortest travel times as expected. However, it is not highly likely to encounter totally clustered service regions in real life. Although density of customers' requests can be accumulated in some regions, there are also some requests from out of these dense areas as in the scenario of RC. Compared to pure clusters (C), RC causes around $22 \%$ and $12 \%$ longer travel times whereas R causes $47 \%$ and $37 \%$ longer travel times. It is also worthwhile to mention that the increase in the number of customers rises the travel time by around $35 \%$ in the $\mathrm{C}$ region while it only increases the travel time by around $20 \%$ in the $\mathrm{RC}$ region.

Table 2. Average times for 60-minute time window based on 30 trials

\begin{tabular}{|c|c|l|l|l|l|l|l|}
\hline Customer & Region & $\begin{array}{l}\text { VRPSDP } \\
\text { (Minute) }\end{array}$ & $\begin{array}{l}\mathbf{9 5 \%} \\
\text { CI (+/-) }\end{array}$ & $\begin{array}{l}\text { VRPSDPTW } \\
\text { (Minute) }\end{array}$ & $\begin{array}{l}\mathbf{9 5 \%} \\
\text { CI (+/-) }\end{array}$ & $\begin{array}{l}\text { Difference } \\
\text { (Minute) }\end{array}$ & T-Test \\
\hline \multirow{3}{*}{$\mathbf{2 5}$} & $\mathbf{R}$ & 407.73 & 7.24 & 550.21 & 15.48 & 142.48 & $1.5 \mathrm{E}-24$ \\
\cline { 2 - 8 } & $\mathbf{C}$ & 347.38 & 6.01 & 444.58 & 10.79 & 97.19 & $2.3 \mathrm{E}-23$ \\
\cline { 2 - 8 } & RC & 381.38 & 5.61 & 505.80 & 10.87 & 124.42 & $7.1 \mathrm{E}-29$ \\
\hline
\end{tabular}




\begin{tabular}{|c|c|l|l|l|l|l|l|}
\hline \multirow{3}{*}{35} & $\mathbf{R}$ & 514.30 & 7.06 & 694.21 & 13.78 & 179.91 & $6.9 \mathrm{E}-32$ \\
\cline { 2 - 8 } & $\mathbf{C}$ & 433.57 & 5.68 & 564.04 & 9.11 & 130.46 & $6.5 \mathrm{E}-33$ \\
\cline { 2 - 8 } & $\mathbf{R C}$ & 479.62 & 5.11 & 629.37 & 7.95 & 149.75 & $3.8 \mathrm{E}-39$ \\
\hline
\end{tabular}

Table 3 shows results for the 120-minute time windows. First, p-values are much lower than the threshold value, 0.05 . Therefore, we can say that differences between results are statistically significant. Differences between results change 75 and 135 minutes. The increase in the number of customers affects results between $30 \%$ and $12 \%$ and this is less than the effect when the time window is 60 minutes. Results of RC service area show similar pattern with results for 60-minute time windows while results of $\mathrm{R}$ service region denote significant discrepancies compared to $\mathrm{C}$ service region.

Table 3. Average times for 120-minute time window based on 30 trials

\begin{tabular}{|c|c|c|c|c|c|c|c|}
\hline Customer & Region & $\begin{array}{l}\text { VRPSDP } \\
\text { (Minute) }\end{array}$ & $\begin{array}{l}\text { 95\% CI } \\
(+/-)\end{array}$ & $\begin{array}{l}\text { VRPSDPTW } \\
\text { (Minute) }\end{array}$ & $\begin{array}{l}\mathbf{9 5 \%} \\
\text { CI (+/-) }\end{array}$ & $\begin{array}{l}\text { Difference } \\
\text { (Minute) }\end{array}$ & T-Test \\
\hline \multirow{3}{*}{25} & $\mathbf{R}$ & 407.73 & 7.24 & 510.25 & 13.52 & 102.52 & $4.3 \mathrm{E}-20$ \\
\cline { 2 - 8 } & $\mathbf{C}$ & 347.38 & 6.01 & 422.48 & 9.91 & 75.09 & $1.7 \mathrm{E}-19$ \\
\cline { 2 - 8 } & $\mathbf{R C}$ & 381.38 & 5.61 & 477.33 & 9.42 & 95.95 & $1.4 \mathrm{E}-25$ \\
\hline \multirow{3}{*}{35} & $\mathbf{R}$ & 514.30 & 7.06 & 647.63 & 12.21 & 133.33 & $2.9 \mathrm{E}-27$ \\
\cline { 2 - 8 } & $\mathbf{C}$ & 433.57 & 5.68 & 528.77 & 7.86 & 95.20 & $4.3 \mathrm{E}-28$ \\
\cline { 2 - 8 } & $\mathbf{R C}$ & 479.62 & 5.11 & 588.15 & 7.91 & 108.52 & $1.1 \mathrm{E}-31$ \\
\hline
\end{tabular}

Table 4 denotes results for the 240-minute time windows. First, p-values are much lower than the threshold value, 0.05 . Thus, we can reject the null hypothesis and say average travel times of problems are statistically different. The effect of number of customers significantly decreases as the effect of service regions increases. For RC service area, the increase in the number of customers does not change results remarkably. However, different service regions rise travel times by up to $70 \%$ for 25 customers and $50 \%$ for 35 customers.

Table 4. Average times for 240-minute time window based on 30 trials

\begin{tabular}{|c|c|c|c|c|c|c|c|}
\hline Customer & Region & $\begin{array}{l}\text { VRPSDP } \\
\text { (Minute) }\end{array}$ & $\begin{array}{l}\text { 95\% CI } \\
(+/-)\end{array}$ & $\begin{array}{l}\text { VRPSDPTW } \\
\text { (Minute) }\end{array}$ & $\begin{array}{l}\text { 95\% CI } \\
(+/-)\end{array}$ & $\begin{array}{l}\text { Difference } \\
\text { (Minute) }\end{array}$ & T-Test \\
\hline \multirow{3}{*}{25} & $\mathbf{R}$ & 407.73 & 7.24 & 463.24 & 11.13 & 55.50 & $3.7 \mathrm{E}-12$ \\
\cline { 2 - 9 } & $\mathbf{C}$ & 347.38 & 6.01 & 379.35 & 7.14 & 31.96 & $1.4 \mathrm{E}-09$ \\
\cline { 2 - 8 } & $\mathbf{R C}$ & 381.38 & 5.61 & 430.98 & 8.70 & 49.60 & $3.3 \mathrm{E}-14$ \\
\hline \multirow{3}{*}{35} & $\mathbf{R}$ & 514.30 & 7.06 & 578.99 & 9.96 & 64.69 & $7.1 \mathrm{E}-16$ \\
\cline { 2 - 9 } & $\mathbf{C}$ & 433.57 & 5.68 & 476.94 & 5.65 & 43.36 & $3.2 \mathrm{E}-16$ \\
\cline { 2 - 8 } & $\mathbf{R C}$ & 479.62 & 5.11 & 528.12 & 6.30 & 48.50 & $5.4 \mathrm{E}-18$ \\
\hline
\end{tabular}

Figure 1 shows average travel time differences between VRPSDP and VRPSDPTW with threetime windows change in regard of different test sets. Lines tend to get straight when time windows are getting wider. It means that results are getting more sensitive for different problem settings in short time windows. 


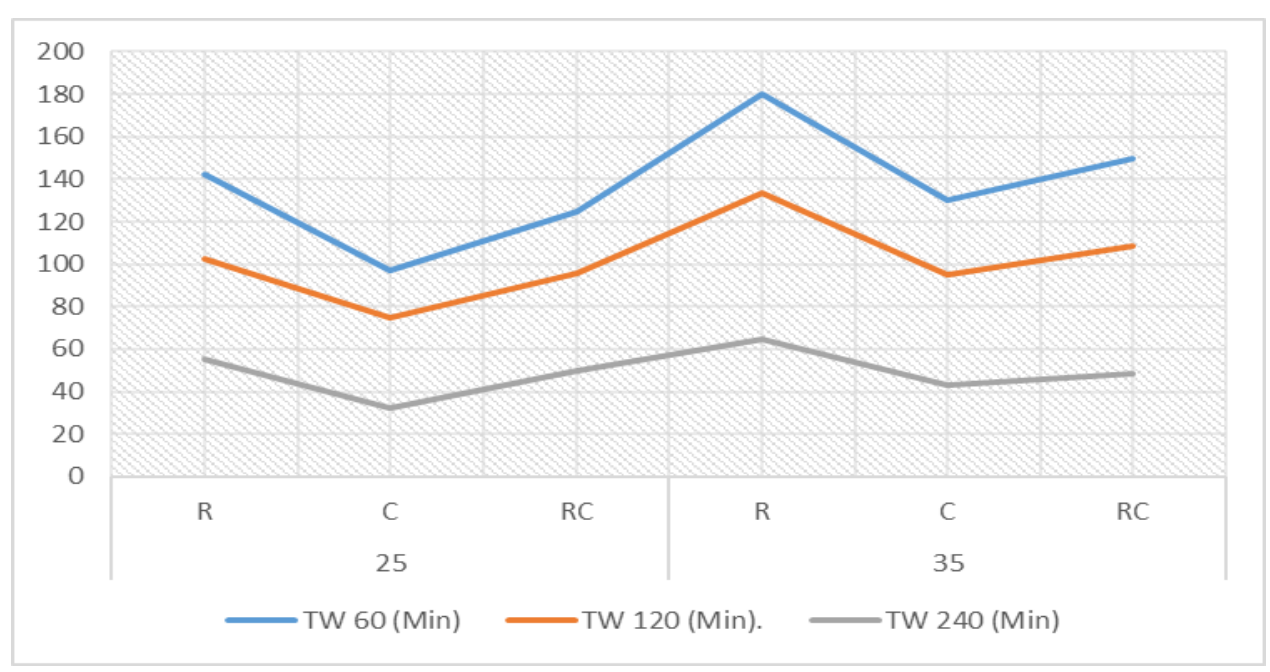

Figure 1. Average travel time differences between VRPSPD and VRPSPDTW according to threetime windows (TW: Time Windows)

The main objective of this study is to provide a tactical or strategic level pricing policy based on different scenarios companies can come across during their operations. However, providing exact prices is impossible without having exact operational costs for companies. This cost can vary company by company, city by city, country by country. Therefore, we can provide a generic price calculation method based on experimental settings in this study. Let us assume that hourly operational cost of a company is $k$ Turkish Liras (TL). If the company is running operations in RC type service area and serves 25 customers, daily additional cost for offering a 60-minute time window to customers is $2.07(124.42 / 60)$ $* k$. Average additional price per customer is $2.07 * k / 25$. For example, if $k$ equals $100 \mathrm{TL}$, average extra price per customer will be $8.29 \mathrm{TL}(2.07 * 100 / 25)$. In other words, a customer should pay additional 8.29 TL to be visited in an hour time window he/she has selected before. In this condition, the company does not lose profits. Table 5 shows average additional prices (TL) per customer for 100 TL hourly operational cost. Service regions and time windows significantly effect additional prices while effect of the number of customers is relatively moderate. Prices in Table 5 are calculated based on simulation settings of this study and 100 TL hourly operational cost given as an example. Note that it is quite easy to adapt different issues, restrictions, and cost factors related to demands of companies into this study.

Table 5. Average additional prices (TL) per customer for 100 TL hourly operational cost

\begin{tabular}{|c|c|c|c|c|c|c|}
\hline \multirow{2}{*}{$\begin{array}{l}\text { Time } \\
\text { Window } \\
\text { (Minute) }\end{array}$} & \multicolumn{3}{|c|}{$\mathbf{2 5}$} & \multicolumn{3}{|c|}{$\mathbf{3 5}$} \\
\cline { 2 - 7 } & $\mathbf{R}$ & $\mathbf{C}$ & $\mathbf{R C}$ & $\mathbf{R}$ & $\mathbf{C}$ & $\mathbf{R C}$ \\
\hline 60 & 9.50 & 6.48 & 8.29 & 8.57 & 6.21 & 7.13 \\
\hline 120 & 6.83 & 5.01 & 6.40 & 6.35 & 4.53 & 5.17 \\
\hline 240 & 3.70 & 2.13 & 3.31 & 3.08 & 2.06 & 2.31 \\
\hline
\end{tabular}

\section{CONCLUSION}

Vehicle Routing Problem with Simultaneous Pickup and Delivery (VRPSPD) has become a popular problem in online grocery, parcel delivery, reverse logistic particularly since high competitions among companies and environmental concerns push companies to decrease costs and carbon footprints. 
Furthermore, customers are more willing to choose visit times due to their hectic business life and daily schedules. On one hand, assigning visit times to customers according to calculated optimal routes and schedules is more profitable for companies. On the other hand, pushing customers to accepted predetermined visit times can cause loss of customers in the high competition environment. Therefore, companies need a new strategy that satisfies visit time preferences of customers when pricing the preferences in order to keep profits.

In this study, a new methodology is proposed to determine a tactical or strategic pricing policy for companies that deal with VRPSPD and time windows (VRPSPDTW). The basic principle is to understand how visit time preferences of customers increase average travel times compared to visit times offered by companies according to calculated optimal routes. To be able to calculate average daily travel times for customers with/without visit time preferences, we conduct 30 trials by considering different customer sets, service regions, and time windows. In each trial, two mixed integer linear programming (MILP) problems are solved based on same customer sets. In the first case, VRPSPD is solved. Next, VRPSPDTW is solved by allowing same customers to select one of three visit time windows. We conduct t-tests to see whether differences between average travel times are statistically significant and calculate confidence intervals.

First, differences between results are statistically significant. The differences between results varies from approximately 100 to 180 minutes for the 60-minute time window. In other words, if we let customer to select one-hour visit time during a day, as between 9 and 10 am or 2 and $3 \mathrm{pm}$, this situation increases average travel times by between $28 \%$ and $35 \%$ compared to the scenario in where visit times are assigned according to optimal routes. Although gaps between results of both problems are getting closer when increasing time windows to 120 and 240 minutes, they are still considerably high, between $21 \%$ and $25 \%$ for 120 -minute, between $10 \%$ and $13 \%$ for 240 -minute time windows. Even customers are allowed to select only morning or afternoon to be visited, this costs the company up to $13 \%$ more average travel times. The other important point is that differences between average travel times notably change according to the number of customers and different service areas. Ten more customers and the service area where locations of customers are distributed equally likely increase the average difference around $80 \%$ for the 60 -minute time window compared to the service area where locations of customers are distributed in three clusters.

It is not possible to provide exact prices according to different time windows unless we exactly know cost factors related to operations of companies. However, once hourly operation cost of a company is known, an approximate pricing policy is quickly determined according to the number of customers, service areas, and the length of time windows. Our experimental settings are configured to be able to understand how some standard real-life issues such as different type service regions, the number of customers, and time windows change results. The other issues companies can encounter during their operations are easily adapted to our model as well.

The most important limitation in this study is to use mathematical models to solve MILPs. As we mentioned before, VRP and its extensions are in NP Hard class and exact solution methods work for only small problem instances. Although a 45-customer set was also considered in the problem, CPLEX fails to find optimal solutions for many scenarios in 3600-second run times. To be able overcome this 
drawback in future, we plan to develop heuristic/metaheuristic solution methods for larger instance problems.

\section{References}

[1] Dantzig, G. B., \& Ramser, J. H. (1959). The Truck Dispatching Problem. Management science, 6(1), 80-91.

[2] Laporte, G. (2009). Fifty years of vehicle routing. Transportation Science, 43(4), 408-416.

[3] Dethloff, J. (2001). Vehicle routing and reverse logistics : the vehicle routing problem with simultaneous delivery and pick-up. OR Spektrum, 23(1), 79-96.

[4] Montané, F. A. T., \& Galvao, R. D. (2006). A tabu search algorithm for the vehicle routing problem with simultaneous pick-up and delivery service. Computers \& Operations Research, 33(3), 595-619.

[5] Golden, B. L., Raghavan, S., \& Wasil, E. A. (Eds.) (2008). The vehicle routing problem: Latest advances and new challenges. Springer Science \& Business Media, 43.

[6] Min, H. (1989). The multiple vehicle routing problem with simultaneous delivery and pick-up points. Transportation Research Part A: General, 23(5), 377-386.

[7] Goksal, F. P., Karaoglan, I., \& Altiparmak, F. (2013). A hybrid discrete particle swarm optimization for vehicle routing problem with simultaneous pickup and delivery. Computers \& Industrial Engineering, 65(1), 39-53.

[8] Yazgan, H. R., \& Büyükyilmaz, R. G. (2017). Eş zamanlı topla dağıt araç rotalama problemine sezgisel bir çözüm yaklaşımı. Sakarya Üniversitesi Fen Bilimleri Enstitüsü Dergisi, 22(2), 436-449.

[9] Kececi, B., Altiparmak, F., \& İmdat, K. (2015). Heterojen Eş-Zamanli Topla-Dağit Araç Rotalama Problemi: Matematiksel Modeller Ve Sezgisel Bir Algoritma. Journal of the Faculty of Engineering and Architecture of Gazi University, 30(2), 185-195.

[10] Hezer, S. and Kara, Y. (2013). Eşzamanli dağitimli ve toplamali araç rotalama problemlerinin çözümü için bakteriyel besin arama optimizasyonu tabanli bir algoritma. Journal of the Faculty of Engineering and Architecture of Gazi University, 28(2), 373-382.

[11] Kalayci, C. B. and Kaya, C. (2016). An ant colony system empowered variable neighborhood search algorithm for the vehicle routing problem with simultaneous pickup and delivery. Expert Systems with Applications, 66, 163-175.

[12] Koç, Ç. and Laporte, G. (2018). Vehicle routing with backhauls: Review and research perspectives. Computers \& Operations Research, 91, 79-91.

[13] Angelellil, E. and Mansini, R. (2002). The Vehicle Routing Problem with Time Windows and Simultaneous Pick-up and Delivery. Quantitative Approaches to Distribution Logistics and Supply Chain Management, 519, 249-267

[14] Lagos, C., Guerrero, G., Cabrera, E., Moltedo-Perfetti, A., Johnson, F., \& Paredes, F. (2018). An improved particle swarm optimization algorithm for the VRP with simultaneous pickup and delivery and time windows. IEEE Latin America Transactions, 16(6), 1732-1740.

[15] Çetin, S. and Gencer, C. (2010). Kesin Zaman Pencereli - Es Zamanli Dagitim Toplamali Arac 
Rotalama Problemi: Matematiksel Model. Journal of the Faculty of Engineering and Architecture of Gazi University, 25(3), 579-585.

[16] Çetin, S. and Gencer, C. (2011). Heterojen Araç Filolu Zaman Pencereli Eş Zamanlı DağıtımToplamalı Araç Rotalama Problemleri: Matematiksel Model. Uluslararası Mühendislik Araştırma ve Geliştirme Dergisi, 3(1), 19-27.

[17] Wang, J., Zhou, Y., Wang, Y., Zhang, J., Chen, C. P., \& Zheng, Z. (2016). Multiobjective Vehicle Routing Problems with Simultaneous Delivery and Pickup and Time Windows: Formulation, Instances, and Algorithms. IEEE Transactions on Cybernetics, 46(3), 582-594.

[18] Wang, C., Mu, D., Zhao, F., \& Sutherland, J. W. (2015). A parallel simulated annealing method for the vehicle routing problem with simultaneous pickup-delivery and time windows. Computers \& Industrial Engineering, 83, 111-122.

[19] Liu, R., Xie, X., Augusto, V., \& Rodriguez, C. (2013). Heuristic algorithms for a vehicle routing problem with simultaneous delivery and pickup and time windows in home health care. European Journal of Operational Research, 230(3), 475-486. 